( К.Д. Иевлева*, Т.А. Баирова, Е.А. Шенеман, В.В. Бальжиева, Ж.Г. Аюрова, Л.В. Рычкова, Л.И. Колесникова

ФГБНУ «Научный центр проблем здоровья семьи и репродукции человека», Иркутск, Россия

Обоснование. Ген рецептора меланокортина 4 (MC4R) кодирует информацию об одноименном рецепторе, экспрессируемом в гипоталамусе и участвующем в регуляции массы тела и роста. Данные о вкладе полиморфизма $M C 4 R$ rs17782313 противоречивы.

Цель исследования - изучить влияние носительства полиморфизма MC4R rs 17782313 на антропометрические параметры у подростков разных этнических групп: европеоидов и монголоидов, проживающих на территории Сибири.

Методы. В исследование включены 179 подростков европеоидной расы (на примере русских, средний воз-

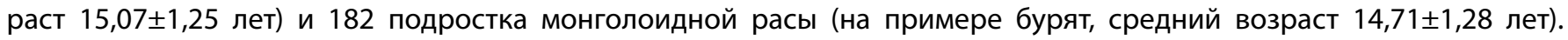
В группы с избыточной массой тела и ожирением (SDS ИMT>1) вошли 89 и 92 подростка, в контрольные группы (SDS ИМТ от -1 до +1) - 90 и 90 подростков русской и бурятской национальностей соответственно. Антропометрическое обследование включало измерение роста, массы тела с расчетом ИМТ (индекс массы тела) и SDS ИМТ (коэффициент стандартного отклонения ИМТ), ОТ (объем талии), ОБ (объем бедер). Генотипирование ДНК-образов, выделенных из цельной венозной крови, осуществлялось методом ПЦР в реальном времени. Статистический анализ результатов исследования проводился с использованием программного обеспечения STATISTICA 8.0.

Результаты. Расчет отношения шансов показал отсутствие ассоциации рискового С-аллеля полиморфизма rs 17782313 с избыточной массой тела и ожирением у подростков в выборке русских (22,5\% против 17,9\%; OR=1,34 (p>0,05) и в Bыборке бурят (29,8\% против 24,1\%, OR=1,43 (p>0,05). Выявлено, что у подростков-носителей С-аллеля бурятской национальности наблюдается более высокий рост в обеих группах (контроль: 162,19 см против 157,26 см; $\mathrm{p}=0,019 ;$ основная: 165,24 см против 164,91 см; p=0,041), а также увеличение веса в контрольной группе (52,29 кг против 48,05 кг, p=0,028).

Заключение. Таким образом, выявлена взаимосвязь полиморфизма MC4R rs 17782313 с ростом и весом у подростков бурятской национальности.

КЛЮЧЕВЫЕ СЛОВА: ожирение; избыточная масса тела; рост; подростки; MC4R; европеоиды; монголоиды.

\title{
EFFECT OF MC4R GENE POLYMORPHISM ON FOOD INTAKE IN ADOLESCENTS WITH OVERWEIGHT AND OBESITY
}

\author{
(c) Kseniya D. levleva*, Tatyana A. Bairova, Ekaterina A. Sheneman, Varvara V. Balzhieva, Zhanna G. Ayurova, \\ Lubov V. Rychkova, Lubov I. Kolesnikova
}

Scientific Centre of Family Health and Human Reproduction Problems, Irkutsk, Russia

BACKGROUND: The melanocortin 4 receptor gene (MC4R) codes the receptor expressed in the hypothalamus and involved in the regulation of body mass and height. Data on the association of polymorphism MC4R rs 17782313 with anthropometric parameters are contradictory.

AIMS: to study the influence of the carrier of polymorphism MC4R rs17782313 on the anthropometric parameters in adolescents of different ethnic groups: caucasians and mongoloids living in the Siberia.

MATERIALS AND METHODS: The study included 179 caucasian adolescents (by the example of russians, average age is 15.07 \pm 1.25 years) and 182 mongoloid adolescents (by the example of the buryats, the average age is $14.71 \pm 1.28$ years), 89 and 92 adolescents were included in groups with overweight and obesity (standard deviation (SDS) BMI> 1), in the control groups (SDS BMI from -1 to +1 ) also 90 and 90 adolescents were included in the control groups (SDS BMI from -1 to +1 ) (russian and buryat, respectively). Anthropometric measurements included height, weight with the calculation of BMI and SDS BMI, WC (waist circumference), HC (hip circumference ). Genotyping was performed by real-time PCR. Statistical analysis of the results of the study was carried out using the software «STATISTICA 8.0».

RESULTS: We showed no association of the risky C-allele of polymorphism rs 17782313 with overweight and obesity in russian adolescents $(22.5 \%$ vs $17.9 \%$ OR $=1.34(p>0.05))$ and in the buryat $(29.8 \%$ vs $24.1 \%, O R=1.43$ ( $p>0.05)$ ). It was revealed that adolescent carriers of the C-allele in buryat showed higher growth in both groups (control: $162.19 \mathrm{~cm}$ vs $157.26 \mathrm{~cm}(p=0.019)$ ), the main group: $165.24 \mathrm{~cm}$ vs $164.91 \mathrm{~cm}(p=0.041))$, as well as weight gain in the control group $(52.29 \mathrm{~kg}$ vs $48.05 \mathrm{~kg}(p=0.028))$. CONCLUSIONS: Thus, the study revealed the relationship of MC4R rs17782313 polymorphism with height and weight in adolescents of buryat ethnic group.

KEYWORDS: obesity; overweight; adolescents; MC4R; food intake. 


\section{ОБОСНОВАНИЕ}

Ожирение - это комплексное заболевание, в основе которого лежит взаимодействие факторов среды и генетической предрасположенности. К настоящему моменту ожирением страдают более 30\% населения мира (BO3, 2014). Наравне с увеличением количества взрослого населения, страдающего избыточной массой тела и ожирением, наблюдается рост числа детей и подростков с установленными диагнозами ожирения [1, 2, 3].

Вопрос о роли наследственности в формировании ожирения до настоящего время остается спорным [4]. Описаны независимые локусы, ассоциированные с ожирением и избыточной массой тела (ИМТ). Особое место среди них занимают гены энергетического обмена: ген рецептора меланокортина 4 (MC4R); ген, ответственный за накопление жировой массы (FTO), ген лептина (LEP), ген рецептора лептина (LEPR) и др. [5].

Ген рецептора меланокортина 4 (MC4R) расположен на длинном плече 18 хромосомы (q21.32). Он кодирует информацию о рецепторе MC4R, который экспрессируется в гипоталамусе, в центре, ответственном за контроль аппетита [6]. Наряду с мутациями MC4R, вызывающими моногенные формы ожирения, описаны его полиморфные варианты, ассоциированные с увеличением риска набора массы тела. Одним из наиболее изученных полиморфизмов гена MC4R является вариант rs17782313 (8246C>T). На значимую ассоциацию данного полиморфного локуса с ожирением и в популяции взрослых монголоидов указывает Cheung и соавт. [7], Xi [8] и Wu [9] - у детей монголоидной и европеоидной рас. Во Хi [8] утверждает, что, несмотря на различную распространенность rs17782313 в популяциях, изучаемый полиморфизм оказывает одинаковый эффект на риск развития ожирения у взрослых и детей как в европеоидных, так и в монголоидных выборках. С другой стороны, существуют исследования, опровергающие ассоциацию rs17782313 с развитием ожирения как среди европеоидов, так и среди монголоидов [10, 3].

\section{ЦЕЛЬ}

Целью нашего исследования явилось изучить влияние носительства полиморфного локуса MC4R rs 17782313 на антропометрические параметры у подростков разных этнических групп: европеоидов и монголоидов, проживающих на территории Сибири.

\section{МЕТОДЫ}

Исследование проведено в период с февраля 2015 г. по май 2017 г. на базе клиники Федерального государственного бюджетного научного учреждения «Научный центр проблем здоровья семьи и репродукции человека» и с января 2015 г. по апрель 2016 г. на территории 9 из 15 сельских муниципальных районов Республики Бурятия (Баргузинский, Джидинский, Еравнинский, Закаменский, Кабанский, Курумканский, Мухоршибирский, Окинский, Тункинский районы).

Исследование поперечное. Обследовано 258 (Клиника Научного центра проблем здоровья семьи и репродукции человека) и 1456 (Республика Бурятия) подростков 11-17 лет, из которых в исследование включены
179 подростков европеоидной расы (на примере рус-

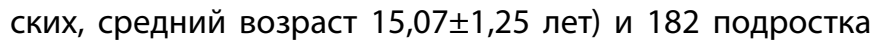
монголоидной расы (на примере бурят, средний возраст $14,71 \pm 1,28$ лет). Национальную принадлежность определяли путем опроса, с выявлением национальности ближайших родственников в третьем поколении.

Проведение исследований одобрено Этическим комитетом ФГБНУ «Научный центр проблем здоровья семьи и репродукции человека» (протокол №6 от 02.12.2015; протокол №9 от 08.10.2014).

Все подростки в каждой этнической выборке разделены на 2 группы: основные группы составили 89 подростков русской национальности и 92 подростков бурятской национальности с избыточной массой тела и ожирением. В контрольные группы вошли 90 подростков русской национальности и 90 подростков бурятской национальности с нормальной массой тела.

Критерии включения в исследование: возраст 13-17 лет, принадлежность к русской/бурятской национальности, SDS ИМТ (SDS - от англ. standart deviation score - коэффициент стандартного отклонения; ИМТ - индекс массы тела) от -1 до +1 (контрольная группа)/SDS ИMT>1 (основная группа), наличие информированного согласия обследуемых и их родителей (возраст обследуемых до 14 лет).

Критерии исключения из исследования: возраст менее 13 и более 17 лет, принадлежность к другим национальностям, соблюдение диеты, отсутствие информированного согласия, наличие заболеваний и эндокринной системы (синдром Кушинга, гипотиреоз, гипоталамическое ожирение, ожирение, обусловленное приемом лекарственных препаратов).

Характеристика исследованных групп представлена в таблице 1.

Антропометрическое обследование проводили по общепринятым методикам. Рост и вес оценивались по перцентильным таблицам Cole и соавт. для данного пола и возраста, с последующим расчетом ИMT и SDS ИMT (коэффициент стандартного отклонения ИМТ) с помощью компьютерной программы Auxology 1,0 b17 (Pfizer, США). Проводилось измерение обхватных параметров, таких как окружность талии - на уровне пупка (при спокойном дыхании) и окружность бедер - в положении стоя (ноги вместе) на уровне латеральных надмыщелков (вертела) бедренных костей (пальпируются на боковой поверхности бедер).

Лабораторные методы исследования включали в себя молекулярно-генетическое тестирование. Кровь забирали в вакуэты объемом 4,0 мл с ЭДТА-консервантом (K3EDTA). Хранение проводили в морозильной камере при температуре $-20^{\circ}$. Экстракцию ДНК проводили из цельной венозной крови коммерческими наборами «ДНК Сорб-Б» («АмплиПрайм», РФ). Амплификация полученных образцов осуществлялась методом полимеразной цепной реакции (ПЦР) в реальном времени на амплификаторе «DT-96» (ДНК-Технология, Россия) с использованием наборов реагентов для генотипирования полиморфного локуса MC4R rs17782313 («Тест Ге», Россия).

Статистический анализ результатов исследования проводился с использованием программного обеспечения STATISTICA 8.0. Определение различий частотных характеристик аллелей и генотипов по исследуемым полиморфизмам осуществлялось с использованием критерия 
Таблица 1. Характеристика исследуемых групп подростков

\begin{tabular}{|c|c|c|c|c|c|}
\hline \multirow[b]{2}{*}{ Параметры } & \multicolumn{2}{|c|}{ Русские, n=179 } & \multicolumn{2}{|c|}{ Буряты, n=182 } & \multirow[b]{2}{*}{$\mathbf{p}$} \\
\hline & $\begin{array}{c}\text { контроль 1, } \\
\text { n=90 }\end{array}$ & $\begin{array}{c}\text { основная } 2 \\
n=89\end{array}$ & $\begin{array}{c}\text { контроль } 3 \\
\text { n=90 }\end{array}$ & $\begin{array}{c}\text { основная } 4 \\
n=92\end{array}$ & \\
\hline \multirow{2}{*}{ Возраст, лет } & 15,29 & 14,85 & 14,89 & 14,52 & $P 1-2=0,022$ \\
\hline & $\pm 1,261$ & $\pm 1,240$ & $\pm 1,3349$ & $\pm 1,2110$ & P3-4=0,441 \\
\hline \multirow{2}{*}{ Рост. см } & 165,40 & 164,83 & 159,62 & 164,135 & $P 1-2=0,709$ \\
\hline & $\pm 8,648$ & $\pm 8,115$ & $\pm 8,7354$ & $\pm 10,480$ & P3-4=0,001 \\
\hline \multirow{2}{*}{ Вес, кг } & 56,67 & 77,60 & 50,02 & 77,46 & P1-2<0,0001 \\
\hline & $\pm 8,292$ & $\pm 12,613$ & $\pm 7,813$ & $\pm 14,091$ & P3-4<0,0001 \\
\hline \multirow{2}{*}{ ИМТ, кг/м2 } & 20,56 & 28,51 & 19,54 & 28,54 & $\mathrm{P} 1-2<0,0001$ \\
\hline & $\pm 1,982$ & $\pm 4,051$ & $\pm 1,438$ & $\pm 3,0193$ & P3-4<0,0001 \\
\hline \multirow{2}{*}{ SDS ИMT } & 0,087 & 2,187 & $-0,058$ & 2,234 & $P 1-2<0,0001$ \\
\hline & $\pm 0,6162$ & $\pm 0,6196$ & $\pm 0,5172$ & $\pm 0,4104$ & P3-4<0,0001 \\
\hline
\end{tabular}

Хи-квадрат. Для определения степени риска развития избыточной массы тела и ожирения при носительстве рисковой аллели производился расчет отношения шансов (ОШ). Сравнительный анализ исследуемых групп, согласно полученным генотипам, по антропометрическим параметрам и показателям питания (калории, белки, жиры, углеводы) производился непараметрическим методом Манна-Уитни.

\section{РЕЗУЛЬТАТЫ}

Частотные характеристики встречаемости полиморфного локуса MC4R (rs17782313) в исследуемых выборках представлены в таблице 2.

Нами не выявлено значимых различий частот генотипов и аллелей изучаемого полиморфного локуса между группой контроля и группой с избыточной массой тела и ожирением как для европеоидной выборки, так и для монголоидной. Расчет ОШ также не выявил увеличения частоты встречаемости рискового С-аллеля исследуемого полиморфизма у подростков, страдающих избыточной массой тела и ожирением.

Результаты сравнительного анализа антропометрических параметров у подростков - носителей разных генотипов изучаемых полиморфных локусов представлены в таблице 3. В связи с низкой частотой встречаемости С-аллеля, носители СС и СТ генотипов объединены в одну группу.

По результатам проведенного анализа выявлено, что носители C-аллеля полиморфизма rs17782313 гена MC4R из выборки подростков бурятской национальности име- ли более высокий рост как в контрольной $(p=0,019)$, так и в основной $(p=0,041)$ группах. Кроме того, в контрольной группе выявлена значимо более высокая масса тела у носителей C-аллеля ( $\mathrm{p}=0,028)$. При этом в выборке русских не обнаружено значимых ассоциаций полиморфизмa rs17782313 с антропометрическими параметрами.

Некоторыми исследователями показано, что носительство С-аллеля полиморфизма rs17782313 у взрослых в большей степени ассоциировано с ИМТ>30 кг/м2 [11]. В нашей выборке подростков с избыточной массой тела и ожирением ИМТ>30 кг/м2 выявлен у 31 человека, из них 12 человек являлись носителями С-аллеля (38,8\%), тогда как подростки с ИМТ< 30кг/м2 составили 59 человек, из которых 26 являлись носителями С-аллеля (44,1\%). Значимых различий частоты носительства полиморфизма rs17782313 у подростков с избыточной массой тела и ожирением между группой с ИМТ>30 кг/м2 и группой с ИМТ <30 кг/м2 не выявлено $(p=0,781)$.

\section{ОБСУЖДЕНИЕ}

Регуляция энергетического обмена и массы тела представляет собой сложный процесс с вовлечением различных систем и тканей организма человека. Особую роль в регуляции обмена энергии занимает гипоталамус, где располагаются центры контроля аппетита и насыщения. Они представлены двумя пулами нейронов. Один пул нейронов продуцирует нейропептид Ү (HПY) и агутиподобный белок (АПБ), другой пул клеток - проопиомеланокортин (ПОМК) и кокаин-амфетамин-регулируемый транскрипт (КАРТ) [12].

Таблица 2. Распределение частот генотипов и аллелей полиморфизма MC4R (rs17782313) в исследуемых группах.

\begin{tabular}{|c|c|c|c|c|}
\hline & \multicolumn{2}{|c|}{ Русские } & \multicolumn{2}{|c|}{ Буряты } \\
\hline & контроль, n=89 & основная, $\mathrm{n}=91$ & контроль, n=89 & основная, $n=89$ \\
\hline CC, \% & $1(1,1)$ & $3(3,3)$ & $2(2,3)$ & $4(4,5)$ \\
\hline $\mathrm{CT}, \%$ & $30(33,7)$ & $35(38,5)$ & $39(43,8)$ & $45(50,6)$ \\
\hline TT, \% & $58(65,2)$ & $53(58,2)$ & $48(53,9)$ & $40(44,9)$ \\
\hline$C, \%$ & $17,9 \%$ & $22,5 \%$ & $24,1 \%$ & $29,8 \%$ \\
\hline$p$ & \multicolumn{2}{|c|}{$\begin{array}{c}\mathrm{P}_{\text {генотипы }}=0,452 \mathrm{P}_{\text {аллели }}=0,443 \\
\mathrm{OR}=1,34(\mathrm{p}>0.05)\end{array}$} & \multicolumn{2}{|c|}{$\begin{array}{c}\mathrm{P}_{\text {генотипы }}=0,402 \mathrm{P}_{\text {аллели }}=0,393 \\
\mathrm{OR}=1,43(\mathrm{p}>0.05)\end{array}$} \\
\hline
\end{tabular}

Сокращения: $\mathrm{C}$ - цитозин; T - тимин; OR - от англ. odds ratio - отношение шансов. 
Таблица 3. Антропометрические параметры подростков - носителей разных генотипов полиморфизма MC4R (rs17782313)

\section{контроль}

основная

\begin{tabular}{|c|c|c|c|c|}
\hline \multirow[b]{2}{*}{ Параметр } & & \\
\hline & $C C+C T(1)$ & TT (2) & $C C+C T(1)$ & TT (2) \\
\hline \multicolumn{5}{|c|}{ Русские } \\
\hline Рост, сM & $166,822 \pm 8,8438$ & $164,529 \pm 8,2157$ & $165,236 \pm 7,8799$ & $64,9096 \pm 8,3739$ \\
\hline $\mathrm{p}$ & \multicolumn{2}{|c|}{$P_{1-2}=, 3636$} & \multicolumn{2}{|c|}{$P_{1-2}=0,945$} \\
\hline Вес, кг & $58,329 \pm 8,712$ & $56,053 \pm 7,829$ & $77,35 \pm 12,5815$ & $79,653 \pm 12,005$ \\
\hline $\mathrm{p}$ & \multicolumn{2}{|c|}{$P_{1-2}=0,3075$} & \multicolumn{2}{|c|}{$P_{1-2}=0,239$} \\
\hline ИМТ, кг/м² & $20,8061 \pm 1,7236$ & $20,569 \pm 2,154$ & $28,39 \pm 4,0419$ & $29,163 \pm 3,851$ \\
\hline $\mathrm{p}$ & \multicolumn{2}{|c|}{$P_{1-2}=0,617$} & \multicolumn{2}{|c|}{$P_{1-2}=0,208$} \\
\hline SDS ИMT & $0,1406 \pm 0,6407$ & $0,126 \pm 0,638$ & $2,1365 \pm 0,639$ & $2,3144 \pm 0,547$ \\
\hline $\mathrm{p}$ & \multicolumn{2}{|c|}{$P_{1-2}=0,987$} & \multicolumn{2}{|c|}{$P_{1-2}=0,204$} \\
\hline OT, $\mathrm{CM}$ & $71,225 \pm 6,1303$ & $68,7586 \pm 6,6492$ & $87,052 \pm 9,700$ & $89,451 \pm 10,472$ \\
\hline $\mathrm{p}$ & \multicolumn{2}{|c|}{$P_{1-2}=0,179$} & \multicolumn{2}{|c|}{$P_{1-2}=0,957$} \\
\hline $\mathrm{Ob}, \mathrm{cM}$ & $91,35 \pm 6,716$ & $89,42 \pm 9,681$ & $102,0789 \pm 9,892$ & $100,990 \pm 15,283$ \\
\hline $\mathrm{p}$ & \multicolumn{2}{|c|}{$P_{1-2}=0,368$} & \multicolumn{2}{|c|}{$P_{1-2}=0,731$} \\
\hline OT/OБ & $0,78 \pm 0,054$ & $0,78 \pm 0,173$ & $0,8557 \pm 0,0880$ & $0,9106 \pm 0,2332$ \\
\hline$p$ & \multicolumn{2}{|c|}{$P_{1-2}=0,160$} & \multicolumn{2}{|c|}{$P_{1-2}=0,377$} \\
\hline
\end{tabular}

\section{Буряты}

\begin{tabular}{|c|c|c|c|c|}
\hline Рост, CM & $162,1928 \pm 9,4546$ & $157,266 \pm 7,187$ & $165,236 \pm 7,8799$ & $164,9096 \pm 8,3739$ \\
\hline $\mathrm{p}$ & \multicolumn{2}{|c|}{$P_{1-2}=0,019$} & \multicolumn{2}{|c|}{$P_{1-2}=0,041$} \\
\hline Вес, кг & $52,2907 \pm 8,38313$ & $48,048 \pm 6,5329$ & $77,35 \pm 12,581$ & $79,653 \pm 12,005$ \\
\hline$p$ & \multicolumn{2}{|c|}{$P_{1-2}=0,028$} & \multicolumn{2}{|c|}{$P_{1-2}=0,598$} \\
\hline ИМТ & $19,717 \pm 1,4235$ & $19,434 \pm 1,431$ & $28,3934 \pm 4,041$ & $29,1638 \pm 3,8517$ \\
\hline$p$ & \multicolumn{2}{|c|}{$P_{1-2}=0,447$} & \multicolumn{2}{|c|}{$P_{1-2}=0,157$} \\
\hline SDS ИMT & $-0,0416 \pm 0,556$ & $-0,038 \pm 0,5363$ & $2,239 \pm 0,4000$ & $2,286 \pm 0,355$ \\
\hline $\mathrm{p}$ & \multicolumn{2}{|c|}{$P_{1-2}=0,826$} & \multicolumn{2}{|c|}{$P_{1-2}=0,740$} \\
\hline OT, $\mathrm{cm}$ & $64,785 \pm 7,192$ & $62,816 \pm 6,814$ & $88,245 \pm 8,8795$ & $87,468 \pm 909734$ \\
\hline $\mathrm{p}$ & \multicolumn{2}{|c|}{$P_{1-2}=0,201$} & \multicolumn{2}{|c|}{$P_{1-2}=0,510$} \\
\hline $\mathrm{Ob}, \mathrm{cm}$ & $86,107 \pm 5,7884$ & $82,82 \pm 8,0665$ & $96,653 \pm 9,860$ & $97,676 \pm 10,255$ \\
\hline $\mathrm{p}$ & \multicolumn{2}{|c|}{$P_{1-2}=0,593$} & \multicolumn{2}{|c|}{$P_{1-2}=0,521$} \\
\hline OT/OБ & $0,7519 \pm 0,063$ & $0,7592 \pm 0,0545$ & $0,918 \pm 0,0055$ & $0,900 \pm 0,0805$ \\
\hline $\mathrm{p}$ & \multicolumn{2}{|c|}{$P_{1-2}=0,667$} & \multicolumn{2}{|c|}{$P_{1-2}=0,144$} \\
\hline
\end{tabular}

Сокращения: ИМТ - индекс массы тела; SDS - коэффициент стандартного отклонения; ОТ - окружность талии; ОБ - окружность бедер.

ПОМК - прогормон, кодирующий в составе своей аминокислотной последовательности несколько пептидов, ни один из которых в составе белка-предшественника не активен. Биологическая активность проявляется после расщепления ПОМК в зависимости от конкретных стимулов и места трансдукции: адренокортикотропный гормон (АКТГ) и ү-МСГ (ү-меланоцитстимулирующий гормон) - в передней доле гипофиза; кортикотропиноподобный пептид, бета-эндорфин, гамма-лПГ и а-МСГ (а-меланоцитстимулирующий гормон) - в промежуточной доле гипофиза [13].

Расщепление ПОМК в гипоталамусе регулируется в соответствии с энергетической потребностью. Эта регуляция опосредуется лептином жировой ткани. Лептин является частью петли обратной связи: жировая ткань продуцирует его как гуморальный сигнал, интенсив- ность которого пропорциональна количеству жировой ткани. Сигналы лептина улавливаются и трансдуцируются ПОМК-ергическими нейронами, запускающими расщепление ПОМК до вышеописанных биоактивных пептидов - меланокортинов.

Функции меланоцитстимулирующего гормона опосредуются через рецепторы меланокортина (MCR). Ceмейство MCR состоит из пяти классов G-белковых рецепторов: MC1R - MC5R, которые экспрессируются в разных органах и тканях. Экспрессия MC4R широко распространена в ЦНС: таламусе, гипоталамусе, стволе мозга и коре головного мозга, что определяет плейотропность МСГ [14]. Ключевую роль в регуляции потребления пищи играют MC4R, расположенные на нейронах паравентрикулярных ядер гипоталамуса [15]. Таким образом, MC4R активизируется а-МСГ, который образуется из его пред- 
шественника - ПОМК в результате активации рецепторов лептина, определяя MC4R как важное звено лептин-меланокортиновой регуляции потребления пищи [6].

Мутации в гене MC4R являются наиболее частой причиной развития несиндромального моногенного ожирения. Полиморфные локусы MC4R ассоциированы с развитием мультифакторных форм ожирения [16]. Одним из наиболее изученных является полиморфный локус rs17782313, однако данные о частоте встречаемости рискового С-аллеля и его вкладе в формирование избыточной массы тела/ожирения противоречивы. Rotter I. и соавт. [17], по результатам обследования 272 мужчин- европеоидов в возрасте 50-75 лет не выявили взаимосвязи rs17782313 с массой тела. Не было выявлено данной закономерности и в ходе исследования детей и подростков в Пекине [18].

Loos и соавт. (2009), по результатам мета-анализа 77228 взрослых и 5988 детей в возрасте от 7 до 11 лет, проживающих в Европе, описывают высокую частоту встречаемости рискового С-аллеля как у детей и подростков, так и у взрослых. При этом вклад данного локуса у детей в 2 раза выше, чем у взрослых [16], достигая максимума в 15-20 лет и постепенно ослабевая в последующие возрастные периоды, но сохраняя тенденцию в 53 года [19]. По данным сотрудников Harvard School of Public Health (США), обследовавших женщин с сахарным диабетом в возрасте 54,1 16,7 лет, каждый С-аллель связан с увеличением ИМТ на 0,34 кг/м, окружности талии - на 0,73 см [20]. Уникальное близнецовое исследование, включающее 1890 детей и подростков двух расовых выборок (европеоидов и негроидов), проведено Gaifen Liu и соавт.и (2010) в Огасте (США) [21], по окончании которого авторы сообщили о сопоставимости их результатов с данными [16]: каждая рисковая С-аллель увеличивала вес тела на 2,45 кг, а окружность талии - на 1,6 см, и, как отметили авторы, выявленные закономерности характерны для представителей обеих рас. Во Хі и соавт. [8] на основании метаанализа, включавшего более 300000 респондентов из 61 исследования, указывает на наличие дифференцированного вклада rs17782313 у представителей разных рас. Если для европеоидов ОШ=1,18 (95\% доверительный интервал (ДИ) 1,15-1,21,), для жителей Восточной Азии ОШ=1,24 (95\% ДИ 1,14-1,34), то для африканцев $О Р=1,00,95 \%$ ДИ 0,86-1,16).

Corella и соавт. в выборке взрослых испанцев продемонстрировали увеличение веса на 0,60 кг на каждую рисковую С-аллель (95\% ДИ 0,17-1,03) и роста - на 0,3 См на каждую рисковую С-аллель (95\% ДИ 0,01-0,05), не выявив при этом различий частотных характеристик встречаемости рискового С-аллеля у пациентов с ожирением в сравнении с респондентами с нормальной массой тела [22]. По результатам представленного исследования частота встречаемости рискового С-аллеля высока и составляет 17,9\% - в выборке подростков-европеоидов без избыточной массы тела/ожирения и 24,1\% - в выборке подростков-монголоидов без избыточной массы тела/ ожирения. Распространенность С-аллеля в выборках подростков с нормальным весом (SDS ИМТ от -1 до +2) не отличается от частоты С-аллеля в выборках подростков с избыточной массой тела/ожирением (SDS ИMT>1) в обеих этнических группах: 22,5\% и 29,8\% соответственно $(p=0,44 ; p=0,39)$. По результатам сравнительного анали- за антропометрических параметров у подростков группы контроля и подростков с избыточной массой тела/ ожирением в обеих этнических выборках показано, что большую массу тела имели подростки-монголоиды-носители С-аллеля группы контроля $(162,1928 \pm 9,4546$ см против 157,266 7,187 см, p=0,019). Наряду с этим, как в данной выборке, так и в выборке подростков с избыточной массой тела/ожирением носители С-аллеля имели выше

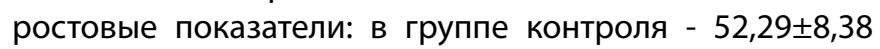
кг против 48,05 $\pm 6,53$ кг ( $p=0,028)$, в группе подростков

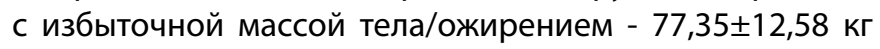

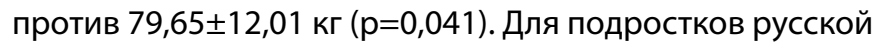
выборки данной зависимости не выявлено. Вместе с тем Loos и соавт. сообщают о наличии взаимосвязи C-аллеля rs17782313 с более высоким ростом у подростков-европеоидов [16].

Основными функциями рецептора меланокортинстимулирующего гормона 4 (MC4R) являются контроль веса тела и регуляция пищевого поведения [23]. Однако центральные MC4-рецепторы могут быть также вовлечены в регуляцию других эффектов меланокортина. Исследования с использованием генетически модифицированных мышей демонстрируют развитие раннего тяжелого ожирения, вызванного гиперфагией и снижением энергетических затрат, в сочетании с увеличением линейного роста, высокой плотностью костей и повышенными уровнями холестерина [24-28].

Накопленные факты взаимосвязи роста и носительства полиморфного локуса гена рецептора MC4R как в эксперименте, так и в клинической практике до настоящего времени не получили объяснения. Одним из вероятных механизмов является снижение обусловленной ожирением супрессии соматотропина под действием недостаточности MC4R [29]. Соматотропин является анаболическим гормоном, активизирующим биосинтез белка, гликогена, ДНК и ускоряющим мобилизацию жиров из депо с распадом жирных кислот. Синтезируется данный гормон в передней доле гипофиза. Основными регуляторами синтеза соматотропина являются соматотропин-рилизинг-фактор (СТГФ) и соматостатин, которые вырабатываются гипоталамусом [30].

Показано, что ожирение и гиперфагия приводят к супрессии соматотропина [31]. При этом имеются данные о том, что недостаточная функция рецепторов MC4R способствует восстановлению выработки соматотропина при ожирении [29]. В Исследовании 4537 индийских детей (средний возраст 10-11 лет) обнаружено, что у 106 детей с мутациями, приводящими к снижению функции MC4R, наблюдалось увеличение роста в среднем на 1,5 см в сравнении с детьми без мутации [32]. Увеличение роста также наблюдалось у подростков и взрослых, страдающих моногенными формами ожирения с ранней манифестацией, обусловленной носительством мутаций гена MC4R. При этом измерение колебаний уровня гормона роста у лиц с ожирением, обусловленным мутацией MC4R, в сравнении с контрольной группой мультифакторного ожирения показало значимую корреляцию носительства мутации с увеличением экспрессии соматотропина до 85\% нормы здоровых людей без ожирения [29]. При этом экспериментальное исследование Tan H.Y. et al. показало, что у мышей с таргетной делецией в гене MC4R, приводящей к его недостаточности, 
не выявлено прямой зависимости между уровнями экспрессии MC4R и соматотропина. Показано, что у этих мышей наблюдалось ускорение линейного роста под действием гиперфагии, но не увеличение уровня соматотропина, что говорит о независимом от соматотропина влиянии недостаточности MC4R на линейный рост. Однако механизм данного влияния не установлен.

\section{ЗАКЛЮЧЕНИЕ}

Таким образом, это первое исследование ассоциации носительства полиморфного локуса MC4R rs17782313 с избыточной массой тела и ожирением в выборках подростков русской и бурятской национальностей, проживающих на территории Восточной Сибири. Нами не выявлена значимая ассоциация данного полиморфизма с избыточной массой тела и ожирением, однако обнаружена взаимосвязь с ростом и весом у подростков бурятской национальности.

\section{ДОПОЛНИТЕЛЬНАЯ ИНФОРМАЦИЯ}

Источник финансирования. Работа выполнена в рамках госбюджетной темы «Кардиометаболические нарушения у детей и подростков как патогенетическая основа формирования высокого кардиоваскулярного риска» (0542-2014-0002).

Конфликт интересов. Авторы заявляют об отсутствии конфликтов интересов.

Участие авторов. Все авторы внесли значимый вклад в проведение исследования и подготовку статьи, прочли и одобрили финальную версию статьи перед публикацией.

\section{СПИСОК ЛИТЕРАТУРЫ | REFERENCES}

1. Дедов И.И., Мельниченко Г.А., Бутрова С.А. Ожирение у подростков в России // Терапевтический архив. - 2007. - №10. - С.28-32. [Dedov II, Mel'nichenko GA, Butrova SA. Ozhirenie u podrostkov v Rossii. Terapevticheskil arkhiv. 2007;(10):28-32. (In Russ.)]

2. Бальжиева В.В., Баирова Т.А., Рычкова Л.В., и др. Этногенетические аспекты ожирения у детей и подростков // Вопросы детской диетологии. - 2017. - Т.15. - №5. - C.29-34. [Balzhieva W, Bairova TA, Rychkova LV, et al. Ethnogenetic aspects of obesity in children and adolescents. Vopr Det Dietol. 2017;15(5):29-34. (In Russ.)] doi: 10.20953/1727-5784-2017-5-29-34

3. Liu G, Zhu H, Dong Y, et al. Influence of common variants in FTO and near INSIG2 and MC4R on growth curves for adiposity in African- and European-American youth. Eur J Epidemiol. 2011;26(6):463-473. doi: 10.1007/s10654-011-9583-4

4. Баирова Т.А., Шенеман Е.А., Рычкова Л.В., Иевлева К.Д. Ген FTO и его роль в развитии ожирения и избыточной массы тела у детей Т.А. // Педиатрия. Журнал им. Г.Н. Сперанского. 2017. - T.96. - №4. - C.186-193. [Bairova TA, Sheneman EA, Rychkova L V, levleva KD. FTO gene and its role in development of obesity and excessive body weight in children. Pediatr J named after GN Speransky. 2017;96(4):186-193 (In Russ.)] doi: 10.24110/0031-403X-2017-96-4-186-193

5. Gahagan S. Overweight and obesity. In: Kliegman RM, Stanton BF, St. Geme JW, Schor NF, eds. Nelson Textbook of Pediatrics. 20th ed. Philadelphia, PA: Elsevier; 2016:chap 47.

6. Hinney A, Volckmar A-L, Knoll N. Melanocortin-4 Receptor in Energy Homeostasis and Obesity Pathogenesis. Prog Mol Biol Trans/ Sci. 2013;114:147-191. doi: 10.1016/B978-0-12-386933-3.00005-4

7. Cheung CYY, Tso AWK, Cheung BMY, et al. Obesity Susceptibility Genetic Variants Identified from Recent Genome-Wide Association Studies: Implications in a Chinese Population. J Clin Endocrinol Metab. 2010;95(3):1395-1403. doi: 10.1210/jc.2009-1465

8. Xi B, Chandak GR, Shen Y, et al. Association between Common Polymorphism near the MC4R Gene and Obesity Risk: A Systematic Review and Meta-Analysis. PLoS One. 2012;7(9):e45731. doi: 10.1371/journal.pone.0045731

9. Wu L, Xi B, Zhang M, et al. Associations of Six Single Nucleotide Polymorphisms in Obesity-Related Genes With BMI and Risk of Obesity in Chinese Children. Diabetes. 2010;59(12):3085-3089. doi: $10.2337 / \mathrm{db} 10-0273$

10. levleva K, Bairova T, Sheneman E, Kolesnikova L. Carriers of mc4r rs 17782313 in female adolescents with overweight and obesity. Acta Paediatr. 2017;106(S470):27-28. doi: 10.1111/apa.14094

11. Srivastava A, Mittal B, Prakash J, et al. Evaluation of MC4R [rs17782313, rs 17700633], AGRP [rs3412352] and POMC [rs1042571] Polymorphisms with Obesity in Northern India. Mittal B, ed. Oman Med J. 2014;29(2):114-118. doi: 10.5001/omj.2014.28
12. Dardeno TA, Chou SH, Moon H-S, Chamberland JP, Fiorenza CG, Mantzoros CS. Leptin in human physiology and therapeutics. Front Neuroendocrinol. 2010;31(3):377-393. doi: 10.1016/j.yfrne.2010.06.002

13. Smith Al, Funder JW. Proopiomelanocortin Processing in the Pituitary, Central Nervous System, and Peripheral Tissues. Endocr Rev. 1988;9(1):159-179. doi: 10.1210/edrv-9-1-159

14. Yang $Y$ Structure, function and regulation of the melanocortin receptors. Eur J Pharmacol. 2011;660(1):125-130. doi: 10.1016/j.ejphar.2010.12.020.

15. Redinger RN. The pathophysiology of obesity and its clinical manifestations. Gastroenterol hepatol (NY). 2007;3(11):856-63.

16. Loos RJF, Lindgren CM, Li S, et al. Common variants near MC4R are associated with fat mass, weight and risk of obesity. Nat Genet. 2008;40(6):768-775. doi: 10.1038/ng.140

17. Rotter I, Skonieczna-Zydecka K, Kosik-Bogacka D, et al. Relationships between FTO rs9939609, MC4R rs17782313, and PPARy rs1801282 polymorphisms and the occurrence of selected metabolic and hormonal disorders in middle-aged and elderly men a preliminary study. Clin Interv Aging. 2016;11(6):1723-1732. doi: 10.2147/CIA.S120253

18. Song J-Y, Song Q-Y, Wang S, et al. Physical Activity and Sedentary Behaviors Modify the Association between Melanocortin 4 Receptor Gene Variant and Obesity in Chinese Children and Adolescents. PLOS One. 2017;12(1):e0170062. doi: 10.1371/journal.pone.0170062

19. Hardy R, Wills AK, Wong A, et al. Life course variations in the associations between FTO and MC4R gene variants and body size. Hum Mol Genet. 2010;19(3):545-552. doi: 10.1093/hmg/ddp504

20. Liu G, Zhu H, Lagou V, et al. Common Variants Near Melanocortin 4 Receptor Are Associated with General and Visceral Adiposity in European- and AfricanAmerican Youth. J Pediatr. 2010;156(4):598-605.e1 doi: 10.1016/j.jpeds.2009.10.037

21. Corella D, Ortega-Azorín C, Sorlí JV, et al. Statistical and Biological Gene-Lifestyle Interactions of MC4R and FTO with Diet and Physical Activity on Obesity: New Effects on Alcohol Consumption. PLoS One. 2012;7(12):e52344. doi: 10.1371/journal.pone.0052344

22. Adan RAH, Tiesjema B, Hillebrand JJG, et al. The MC4 receptor and control of appetite. Br J Pharmacol. 2006;149(7):815-827. doi: 10.1038/sj.bjp.0706929

23. Huszar D, Lynch CA, Fairchild-Huntress V, et al. Targeted Disruption of the Melanocortin-4 Receptor Results in Obesity in Mice. Cell. 1997;88(1):131-141. doi: 10.1016/S0092-8674(00)81865-6

24. Marsh DJ, Hollopeter G, Huszar D, et al. Response of melanocortin-4 receptor-deficient mice to anorectic and orexigenic peptides. Nat Genet. 1999;21(1):119-122. doi: 10.1038/5070

25. Ghamari-Langroudi M, Digby GJ, Sebag JA, et al. G-proteinindependent coupling of MC4R to Kir7.1 in hypothalamic neurons. Nature. 2015;520(7545):94-98. doi: 10.1038/nature14051 
26. Morgan DA, McDaniel LN, Yin T, et al. Regulation of Glucose Tolerance and Sympathetic Activity by MC4R Signaling in the Lateral Hypothalamus. Diabetes. 2015;64(6):1976-1987. doi: 10.2337/db14-1257

27. Balthasar N, Dalgaard LT, Lee CE, et al. Divergence of Melanocortin Pathways in the Control of Food Intake and Energy Expenditure. Cell. 2005;123(3):493-505. doi: 10.1016/j.cell.2005.08.035

28. Martinelli CE, Keogh JM, Greenfield JR, et al. Obesity due to Melanocortin 4 Receptor (MC4R) Deficiency Is Associated with Increased Linear Growth and Final Height, Fasting Hyperinsulinemia, and Incompletely Suppressed Growth Hormone Secretion. J Clin Endocrinol Metab. 2011;96(1):E181-E188. doi: 10.1210/jc.2010-1369
29. Devesa J, Almengló C, Devesa P. Multiple Effects of Growth Hormone in the Body: Is it Really the Hormone for Growth? Clin Med Insights Endocrinol Diabetes. 2016;9:47-71. doi: 10.4137/CMED.S38201

30. Scacchi M, Pincelli Al, Cavagnini F Growth hormone in obesity. Int J Obes. 1999; 23(3):260-7. 1999;23(3):260-271. doi: 10.1038/SJ.IJO.0800807

31. Thearle MS, Muller YL, Hanson RL, et al. Greater Impact of Melanocortin-4 Receptor Deficiency on Rates of Growth and Risk of Type 2 Diabetes During Childhood Compared With Adulthood in Pima Indians. Diabetes. 2012;61(1):250-257. doi: 10.2337/db11-0708

32. Tan HY, Steyn FJ, Huang L, et al. Hyperphagia in male melanocortin 4 receptor deficient mice promotes growth independently of growth hormone. J Physiol. 2016;594(24):7309-7326. doi: 10.1113/JP272770

\section{ИНФОРМАЦИЯ ОБ АВТОРАХ [AUTHORS INFO]:}

* Иевлева Ксения Дмитриевна, аспирант [Kseniya D. levleva, MD, postgraduade student]; Россия, 664003, Иркутск, ул. Тимирязева, д.16 [address: 16 Timiryazeva street, 664003 Irkutsk, Russia]; ORCID: https://orcid.org/0000-0002-0177-234X; eLibrary SPIN: 2743-9932; e-mail: asiy91@mail.ru

Баирова Татьяна Ананьевна, д.м.н. [Tatyana A. Bairova, MD, PhD]; eLibrary SPIN: 2039-3728; e-mail: tbairova38@mail.ru

Шенеман Екатерина Алексеевна, аспирант [Ekaterina A. Sheneman, MD, postgraduade student]; eLibrary SPIN: 4430-5315; e-mail: sheneman@bk.ru

Бальжиева Варвара Владимировна, аспирант [Varvara V. Balzhieva, MD, postgraduade student]; e-mail: varvara.balzhieva@yandex.ru

Аюрова Жанна Гармаевна, аспирант [Zhanna G. Ayurova, MD, postgraduade student]; e-mail:zhanna.irk@mail.ru

Рычкова Любовь Владимировна, д.м.н., професcop [Lubov V. Rychkova, MD, PhD, professor]; ORCID: https://orcid.org/0000-0002-0117-2563; eLibrary SPIN: 1369-6575; e-mail: iphr@sbamsr.irk.ru Колесникова Любовь Ильинична, д.м.н., професcop [Lubov I. Kolesnikova, MD, PhD, professor]; ORCID: https://orcid.org/0000-0003-3354-2992; eLibrary SPIN: 1584-0281; e-mail: iphr@sbamsr.irk.ru

\section{ЦИТИРОВАТЬ:}

Иевлева К.Д., Баирова Т.А., Шенеман Е.А., Бальжиева В.В., Аюрова Ж.Г., Рычкова Л.В., Колесникова Л.И. Влияние полиморфизма гена MC4R на антропометрические параметры у подростков с избыточной массой тела и ожирением // Ожирение и метаболизм. — 2019. - T.16. — №2. — C.22-28. doi: https://doi.org/10.14341/omet9680

\section{TO CITE THIS ARTICLE:}

levleva KD, Bairova TA, Sheneman EA, Balzhieva VV, Ayurova ZG, Rychkova LV, Kolesnikova LI. Effect of MC4R gene polymorphism on food intake in adolescents with overweight and obesity. Obesity and metabolism. 2019;16(2):22-28. doi: https://doi.org/10.14341/omet9680 